Proceedings of the 2012 Winter Simulation Conference

C. Laroque, J. Himmelspach, R. Pasupathy, O. Rose, and A. M. Uhrmacher, eds.

\title{
EFFECTS OF TERRAIN IN COMPUTATIONAL METHODS FOR INDIRECT FIRE
}

\author{
Esa Lappi \\ Mikko Sysikaski \\ Bernt Åkesson \\ Finnish Defence Forces Technical Research Centre \\ Electronics and Information Technology Division \\ P.O. Box 10, FI-11311 Riihimäki, FINLAND
}

Uğur Z. Yildirim

Turkish War Colleges Joint Concept/Doctrine Experimentation Office

TR-34334, Istanbul, TURKEY

\begin{abstract}
Modeling of artillery fire is a well studied concept in military simulations. There are known models which give accurate results, but they usually assume flat terrain with no obstacles. We develop an artillery fire model that takes terrain shapes into account, extending the previous models. We implemented the extended model and used it to compute the effects of firing onto terrains with differing slopes and angles. The results show that taking terrain elevations into account can make drastic differences in kill probabilities compared to the flat earth model.
\end{abstract}

\section{INTRODUCTION}

Field artillery is one of the most important actors in the battlefield, with fragmentation from high explosive ammunition being the principal cause of casualties in modern conflicts (Courtney-Green 1991). In military simulations, this has motivated the search for accurate computational models of artillery fire, and several models of indirect fire exist. Difficulties in modeling indirect fire arise from many random and hard-tomeasure factors that are present in the usage of the artillery. Examples of such uncertainties are the point of burst of the shell and the masses and initial velocities of the fragments (Courtney-Green 1991).

An early approach for indirect fire was to simply assume that targets close to the aimpoint of a round are more likely to be destroyed than those further away from it, and calculate the kill probabilities based on distance to the aimpoint. Such a function can be derived, e.g., by assuming a normally distributed aiming error and a normally distributed kill probability for each round (Washburn 2003). A more sophisticated way is to assume that the round hits a given point and use the shape of the round to calculate the probability that some of the fragments hit and destroy the target. To address the uncertainty in the impact position of the round, this model can be combined with Monte-Carlo simulation that randomly varies the impact point of the round.

An even more advanced approach, presented by Lappi, Pottonen, Mäki, Jokinen, Saira, Åkesson, and Vulli (2008) and used in the Sandis military simulation tool (Lappi 2008), uses numerical integration over the impact position instead of Monte-Carlo simulation to calculate the kill probability. The model uses adaptive integration that picks more integration points in the areas where the kill probability varies greatly. This produces the same result as the Monte-Carlo method, but using two-dimensional adaptive integration gives the steady state in fewer iterations because only few integrations points are used in the areas where 


\section{Lappi, Sysikaski, Åkesson, and Yildirim}

the kill probability does not vary much. Figure 1 gives an example of the integration points produced by the adaptive integration algorithm that the model uses.

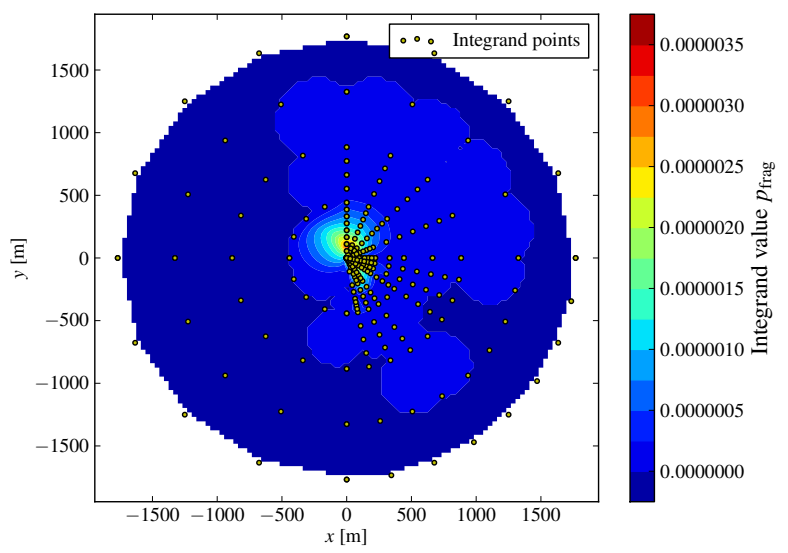

Figure 1: Example of adaptive integration around a target. Colors indicate the kill probabilities from different locations and the yellow points are the evaluated integration points. It can be seen that most integration points are located in areas where the kill probability varies.

The physical model of Lappi et al. (2008) gives accurate results, which have been validated with field tests. The model, however, does not take any terrain shapes into account and assumes completely flat ground. This is a problem in a rugged terrain and in almost any forest environment because even small bumps on the ground can lessen the effect of a low-exploding shell. This can be seen in the article by Koskimaa (1968), where the performance of the ammunition was expressed in terms of lethal area in both open rugged and open flat terrain.

In general the effects of terrain shapes on indirect fire can be divided into two parts: they affect the points of burst of the shells and they provide cover from shell fragments. We present a model which takes both of these effects into account and uses adaptive integration for efficient computation, extending the model of Lappi et al. (2008). An initial version of this extension was presented as a poster by Åkesson and Lappi (2010).

We use an implementation of the extended physical model to calculate the effects of artillery on targets covered by natural obstacles. We used a simplified height map of the area that contained only the elevation information and no vegetation. The physical model for fragmenting ammunition is presented in Section 2 and the extension to the model is described in Section 3. The experimental setup is described in Section 4. The results are presented in Section 5 and their analysis is in Section 6.

\section{A PHYSICAL MODEL FOR FRAGMENTING AMMUNITION}

A numerical model for simulating fragmenting ammunition was presented by Heininen (2006). This paper provides a foundation for calculating the lethality of fragmenting ammunition, based on physical properties. This model was extended by Lappi et al. (2008) to include blast damage and calculation of ammunition impact probabilities, as well as handling of direct hits.

The fragment effect model consists of four components: fragment patterns, a fragment deceleration model, a fragment perforation model and a target element model. A fragmentation warhead is characterized by fragment fans, which are modeled as spherical zones. An illustration of fragment fans for a shell in motion is shown in Figure 2. Due to the velocity of the projectile, the angles of the fans will change and the total initial velocity of the fragments will be the resultant of the projectile velocity and the initial velocity 
in the static case. Fragmentation arena tests can provide experimental data on the warhead fragmentation patterns.

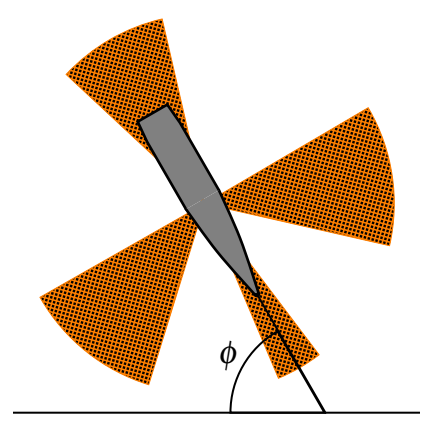

Figure 2: Schematic of the fragment fans of an exploding shell. The angle of fall is denoted by $\phi$.

Each fragment fan has a fragment mass distribution and initial velocity of fragments. A number of distributions for describing fragment masses produced by fragmenting ammunition have been proposed. In this work the Mott distribution (Departments of the Army, the Navy, and the Air Force 1990) was used. It is generally expressed as

$$
N(m)=N_{0} \exp \left(-\sqrt{\frac{2 m}{m_{\mathrm{avg}}}}\right),
$$

where $N(m)$ is the number of fragments with a mass equal to or greater than $m, N_{0}$ is the total number of fragments and $m_{\mathrm{avg}}$ is the average fragment mass.

The deceleration model describes the retardation of fragments due to drag. It is used to compute the impact velocity of the fragments, when the initial velocity, fragment mass and shape and the distance from the point of burst to target are known. The deceleration model can be chosen according to the fragment shape. In this work, the model for natural fragments, proposed by Departments of the Army, the Navy, and the Air Force (1990), Janzon (1971) is used. The velocity $v$ at distance $d$ from the center of the explosion is given by

$$
v(d)=v_{0} \exp \left(-\frac{k d}{m^{1 / 3}}\right)
$$

where $v_{0}[\mathrm{~m} / \mathrm{s}]$ is the initial velocity, $d[\mathrm{~m}]$ is the distance, and $m$ is the fragment mass. The value of the parameter $k$ depends on the shape and velocity of the fragment. For fragments from naturally fragmenting ammunition, the value is simply an average value. In this work, the values proposed by Janzon (1971) are used.

Target elements are described by armor thickness and vulnerable areas from different directions. The perforation capability of fragments is computed using a perforation equation. The perforation equation proposed by Rilbe (1970) is used in this work. According to Rilbe (1970), the penetration depth $e$ [m] is given by

$$
e=q m^{1 / 3} v
$$

where $q$ is a constant, which depends on the fragment shape and material and the target material, $m[\mathrm{~kg}]$ is the fragment mass and $v[\mathrm{~m} / \mathrm{s}]$ is the fragment striking velocity. In (Rilbe 1970), the value $q=39 \cdot 10^{-6}$ $(\mathrm{kg})^{-1 / 3} \mathrm{~s}$ is given for steel fragments striking mild steel plates.

The smallest possible mass for an effective fragment is calculated from Eqs (2) and (3). The number of fragments, $n_{\text {eff }}$, with a mass larger than this is obtained from the fragment mass distribution. The hit probability of a single fragment is the ratio of the projected target area to the area of the fragment fan. 
The probability of a specific target being killed by fragments from a single round is

$$
p_{\text {kill }}=\iint_{A} p_{\text {impact }}(x, y) p_{\text {kill|impact }}(x, y) \mathrm{d} x \mathrm{~d} y,
$$

where $p_{\text {impact }}(x, y)$ is the probability that the round lands at point $(x, y)$ and $p_{\text {killimpact }}(x, y)$ is the probability that the target is killed given that the round impacts $(x, y)$.

\section{EXTENSIONS TO THE PHYSICAL MODEL}

The physical model assumes that the position where the round lands is a random variable following some given distribution, usually the bivariate normal distribution (Lappi et al. 2008). Rounds landing in uneven terrain, however, have a location distribution that depends on the shape of the terrain. Some positions may be impossible to hit because they are blocked by a hill, and for other places the height and the slope of the impact point change the probability. As the hit distribution is defined in some plane parallel to ground level, the probability density of a point at different height should be calculated as projected to the plane in the incoming direction of the round.

The probability of a shell impacting an area depends on the size of the area as "seen" by the shell, the projection of the area to a plane perpendicular to the incoming direction. The size of the projected area depends on the slope of the terrain. The projected area is proportional to the dot product of the incoming direction vector and the normal of the terrain at the point. In practice this means that a round is less likely to hit a downhill location than an uphill one. Figure 3 gives an example of how the hit probabilities change in practice.

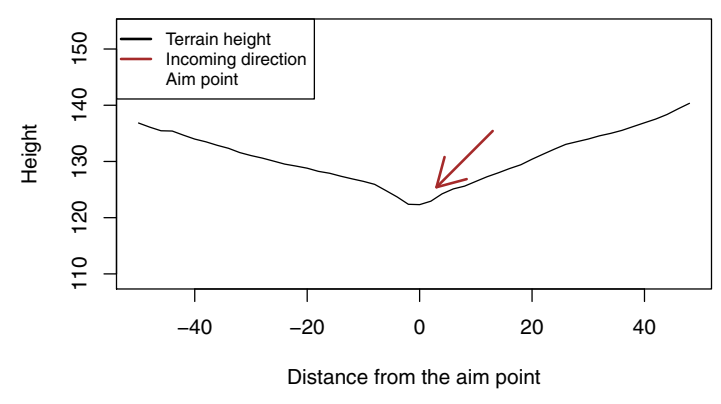

(a) Terrain profile.

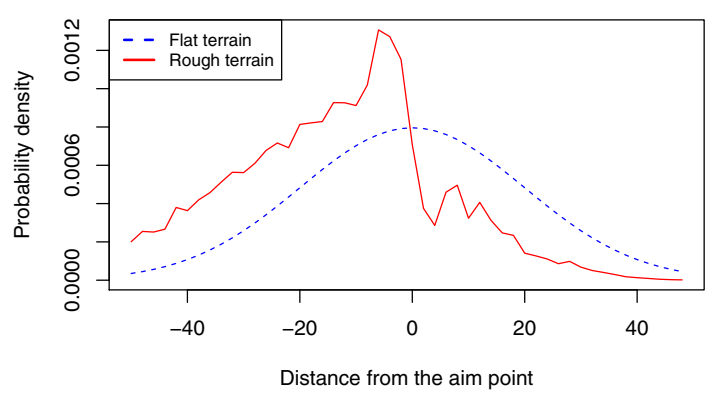

(b) Impact distribution of rounds on flat terrain and on the rough terrain in Figure 3(a).

Figure 3: A cross section of a terrain and its effect on the distribution of the impact point of the round. If we assume flat terrain, the impact points will be normally distributed, as indicated by the dashed blue line in Figure 3(b). However, if the terrain profile in Figure 3(a) is taken into consideration, the impact points will follow the solid red line in Figure 3(b). A round has higher probability to hit an uphill than a downhill location.

In addition to changing the impact position of the round, the terrain provides cover from the fragments of the shell. In this model, we assume that the fragments cannot penetrate the terrain so the fragments do not damage the target if there is no line of sight between the explosion position and the target. Figure 4 illustrates the changes the terrain has in kill probability from a single point of burst. The shell is detonated in the center of the area and kill probabilities in different points are calculated. In some regions, the kill probability drops abruptly to zero, even on flat terrain, due to the geometry of the fragment fans. Gradual changes in kill probability are due to changes in the fragment density.

The physical model uses two-dimensional numerical integration over the hitting position of the round to address some of the various uncertainty factors in indirect fire. For flat terrain, the kill probabilities 


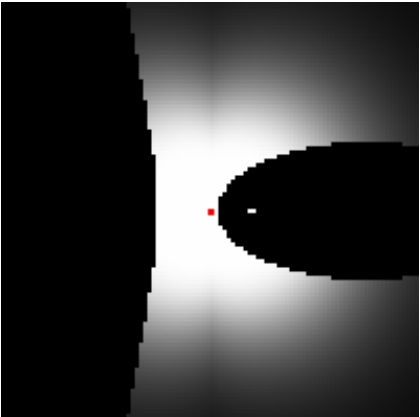

(a) Probability of destroying a target on a flat ground from the center of the area. Lighter color means higher probability. The single white point on the right side of the target is caused by the front fan of the shell.

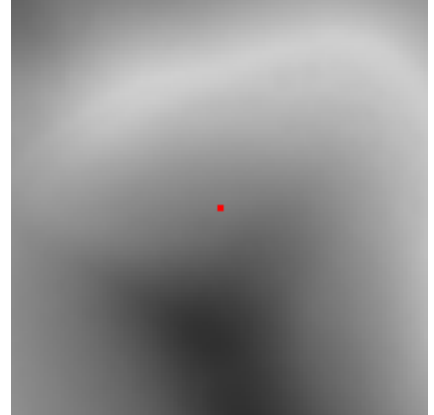

(b) Height map of the area, where lighter color indicates higher elevation. The area is $100 \mathrm{~m} \times$ $100 \mathrm{~m}$.

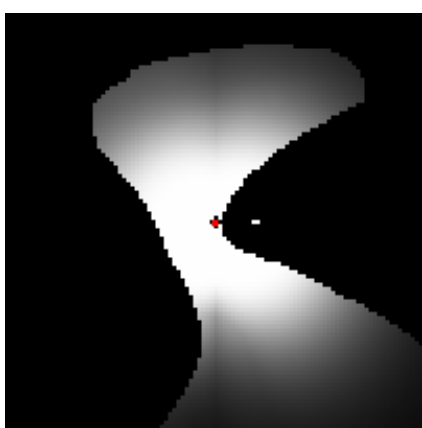

(c) Probability of destroying a target on the terrain shown in the height map to the left. Lighter color means higher probability.

Figure 4: The terrain changes the probability of destroying a target when the shell explodes in the center of the area, indicated by a red dot. The point of burst is located in the center of the figure, indicated by a red dot. The round is fired from the east with $45^{\circ}$ angle of fall and explodes $10 \mathrm{~m}$ above the ground. The kill probability is For some areas the kill probability drops to 0 because of the geometry of the fragment fans and the cover provided by the terrain, and the difference in explosion height changes the effective ranges of the fragment fans. Figure 4(a) shows the probability of destroying a target on flat terrain, and Figure 4(c) shows the probabilities when considering the terrain shown in Figure 4(b).

from different positions change relatively smoothly, but the probability jumps from zero to higher values when the target enters the range of a fragment fan (see Figure 4(a)). For rough terrain, there are even more places where the probability jumps, so using a good adaptive method is even more crucial for the accuracy of the results. In some cases even that might not be enough: there might be a small gap from where the shell can hit the target but not from around it, and the numerical integration fails to notice the gap if none of the initial integration points are placed there. This is usually not a big problem but for very rough terrain it may bring small errors to the result. A potential solution would be to choose the initial set of integration points intelligently based on the terrain shapes but that was beyond the scope of this work.

\section{SETUP AND METHODS USED}

To examine the need and capability for terrain models we studied the effects of shells when firing onto the natural terrain shown in Figure 5. We calculated the hit probabilities to targets located in the marked positions with a $155 \mathrm{~mm}$ high explosive shell. For each of the marked positions we calculated a case with an infantry soldier laying at the height of $0.1 \mathrm{~m}$ from the ground. The position of the soldier is known exactly and a single round is fired aimed at that point from the distance of $6000 \mathrm{~m}$. We assumed that the impact position of a round (on flat ground) is deviated according to a two-dimensional normal distribution. According to Pääesikunta (Defence Command Finland) (1984), the distance implies a standard deviation of $3.5 \mathrm{~m}$ in the deflection direction and a standard deviation of $27 \mathrm{~m}$ in the range direction, and we used those values in the calculations.

We vary the compass direction and the incoming angle as well as the height of burst of the shell and compare the results to the case where we hit the target on flat ground. We use values $20^{\circ}, 30^{\circ}, 45^{\circ}$ and $60^{\circ}$ for the angle of fall of the shell, and use firing directions directly from the east and from the south. For the height of burst we used values $0.1 \mathrm{~m}$ and $10 \mathrm{~m}$, simulating the effects of an impact fuze and a 


\section{Lappi, Sysikaski, Åkesson, and Yildirim}

proximity fuze. We additionally calculated the case where the shell explodes at tangent distance $5.5 \mathrm{~m}$ from the ground, which approximates a forest environment where the shell explodes when it hits a tree.

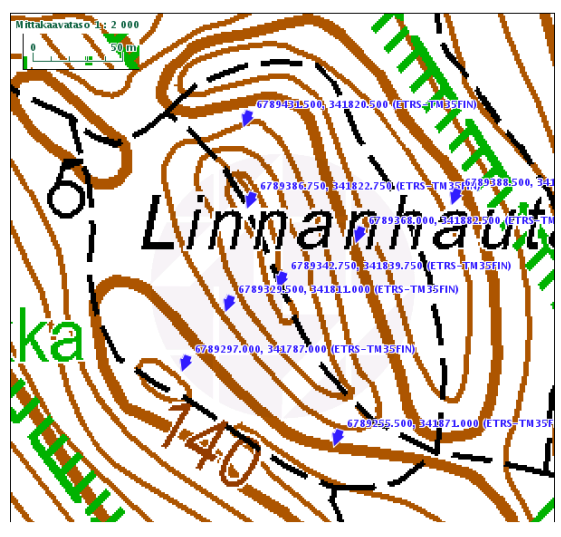

(a) Map of the area.

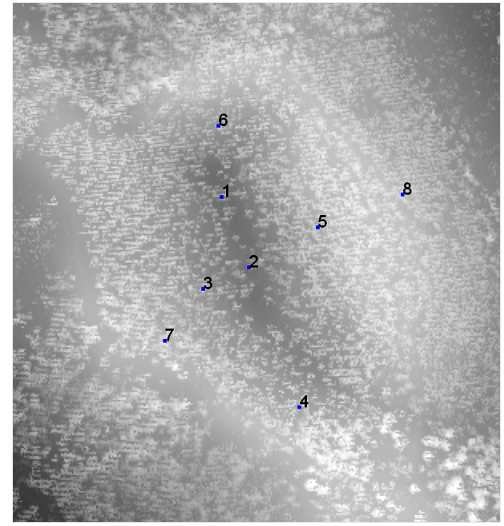

(b) Height model calculated from the laser scan data including vegetation which was filtered out for the computations. Lighter points indicate higher elevation.

Figure 5: The area used in the simulation experiments with the used target points marked.

Our model needs a model of the terrain to calculate its effects into artillery fire. We used laser scanning data provided by the National Land Survey of Finland (2012) as the input data. The laser scanning data was transformed into a height map for efficient use in the computations. The National Land Survey of Finland (2012) laser scanning data has a minimum point density of half a point per square meter and the elevation accuracy of the points is $15 \mathrm{~cm}$. Thus, it is accurate enough for obtaining positions of individual trees in the terrain. In this study, however, we only used the terrain height information because taking the trees into account would risk the numerical stability of adaptive integration.

\section{RESULTS OF THE SIMULATION}

We present the results of the computation at different firing parameters and different targets along with their analysis. Results on flat terrain are shown in Table 1. For a flat terrain model all the heights of burst give high kill probabilities when the angle of fall is high enough. A high angle of fall causes the side fans of a shell to spread on a larger area, which makes them more effective. With low angles of fall the rear fan of a shell may hit the target, which explains why a $20^{\circ}$ angle of fall gives better results than $30^{\circ}$ angle of fall. In the forest case, the height of burst varies with the angle of fall.

Table 1: Target kill probabilities for flat terrain.

\begin{tabular}{|l|c|c|c|c|}
\hline & \multicolumn{4}{|c|}{ Angle of fall (AOF) } \\
\hline Height of burst (HOB) & $20^{\circ}$ & $30^{\circ}$ & $45^{\circ}$ & $60^{\circ}$ \\
\hline $0.1 \mathrm{~m}$ & $7.2 \%$ & $10.2 \%$ & $40.8 \%$ & $41.2 \%$ \\
\hline $10 \mathrm{~m}$ & $18.4 \%$ & $16.1 \%$ & $22.1 \%$ & $41.5 \%$ \\
\hline forest, $\mathrm{HOB}=5.5 \sin (\mathrm{AOF})$ & $14.7 \%$ & $6.3 \%$ & $17.8 \%$ & $52.9 \%$ \\
\hline
\end{tabular}

We show and describe the results of firing at targets located in the positions shown in Figure 5. Detailed positions of individual targets are shown in Figures 6-13. To emphasize the difference to the flat earth model, we display the relative performance of the rounds compared to firing at the target on a flat terrain, 


\section{Lappi, Sysikaski, Åkesson, and Yildirim}

in terms of kill probability. A relative performance value of, e.g., 4.0 means that the kill probability is four times the kill probability when assuming flat terrain (Table 1). These results are shown in Figures 14-16.

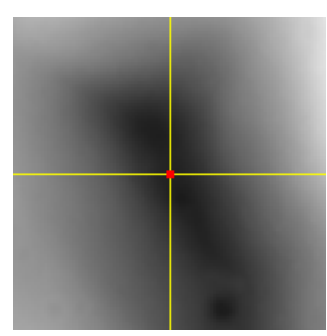

(a) Height map of the area.

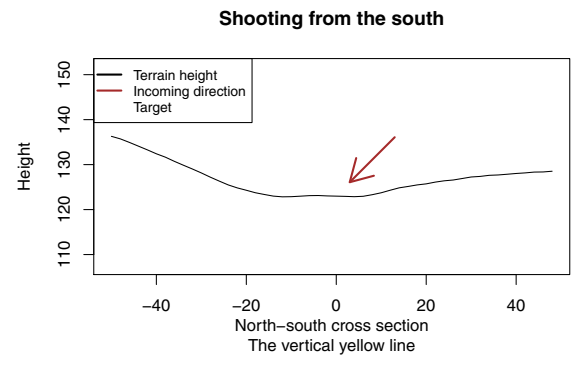

(b) Terrain profile in north-south direction.

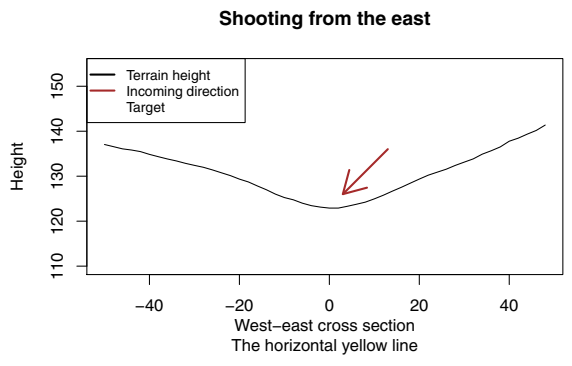

(c) Terrain profile in west-east direction.

Figure 6: Target 1 has some protection from the east so it cannot be well hit with low angles of fall. On the other hand, with high angles of fall the terrain causes the shell to explode even closer to the target compared to flat terrain. The target position is indicated by a red dot.
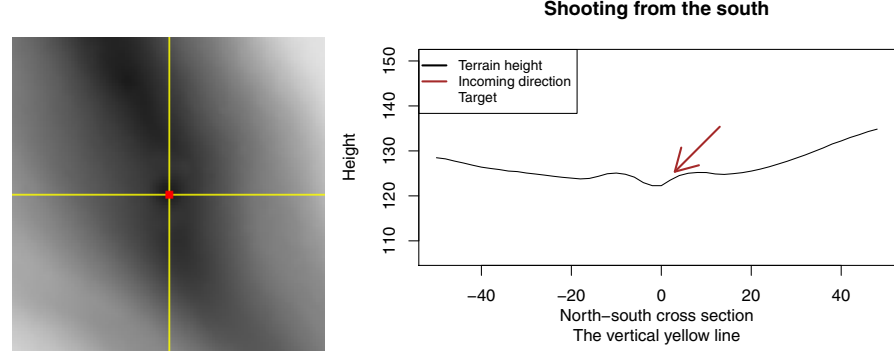

(a) Height map of the (b) Terrain profile in north-south direction. area.

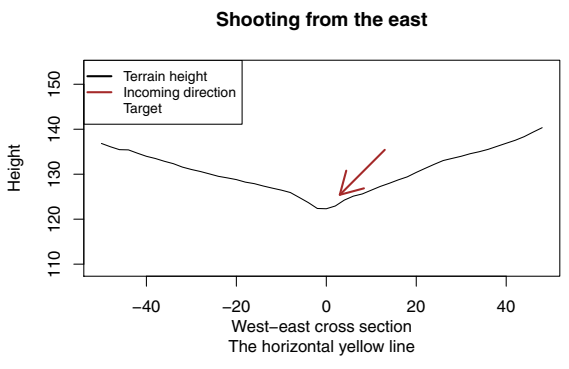

(c) Terrain profile in west-east direction.

Figure 7: Target 2 is in a small hole which gives it good protection from low-exploding shells. Airbursts still work well, except that with $20^{\circ}$ angles of fall the hills prevent them from getting close. The target position is indicated by a red dot.

From the results it can be seen that the kill probabilities on rugged terrain can be either smaller or greater than those on flat terrain. In many cases, such as with impact fuzes detonating close to the ground, the kill probability is smaller due to cover provided by the terrain. However, in some cases the terrain makes the shells more likely to detonate close to the target, which results in higher kill probabilities. Even to any single target the results vary considerably, depending on the angle of fall and direction of fire, implying that there is no simple way to fix the results on flat terrain to match the kill probability on actual terrain.

Figure 17 illustrates this difference by showing the number of rounds required for $90 \%$ kill probabilities in different terrains. For a $10 \mathrm{~m}$ height of burst, the number of rounds is almost four times as many as on flat terrain and for $0.1 \mathrm{~m}$ some targets may not be hit at all or a large number of rounds is required.

\section{CONCLUSIONS}

The simulated results show the magnitude of terrain effects to the combat losses. Just using common sense and imagination, the path of the flying ammunition, the action of the fuze, and the fragment fans combined 

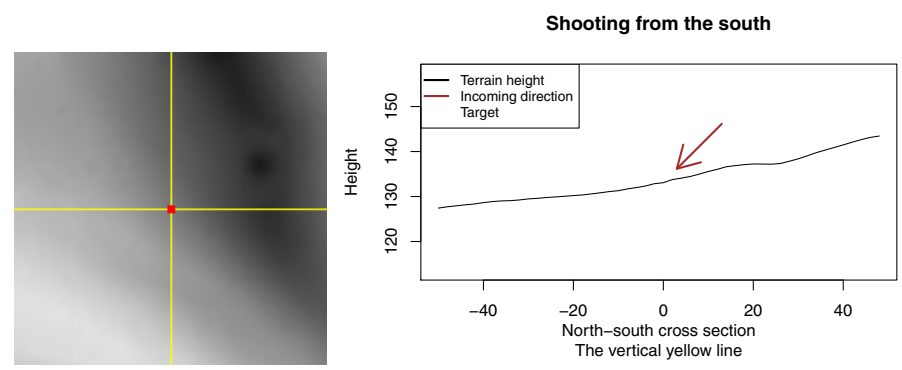

(a) Height map of the (b) Terrain profile in north-south direction. area.

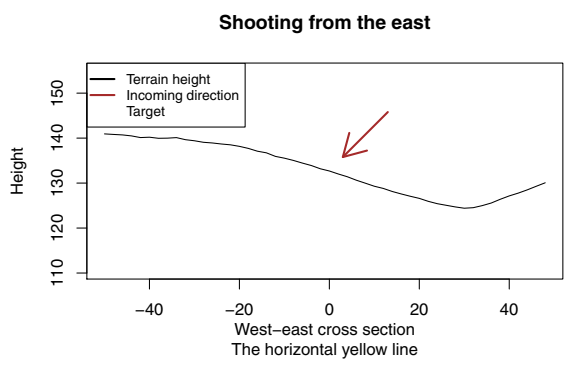

(c) Terrain profile in west-east direction.

Figure 8: Target 3 is on the eastern side of a hill so it can be hit easily from the east. From south the target is in a downhill position, so the the rounds are likely to fall too short or too far behind the target. The target position is indicated by a red dot.
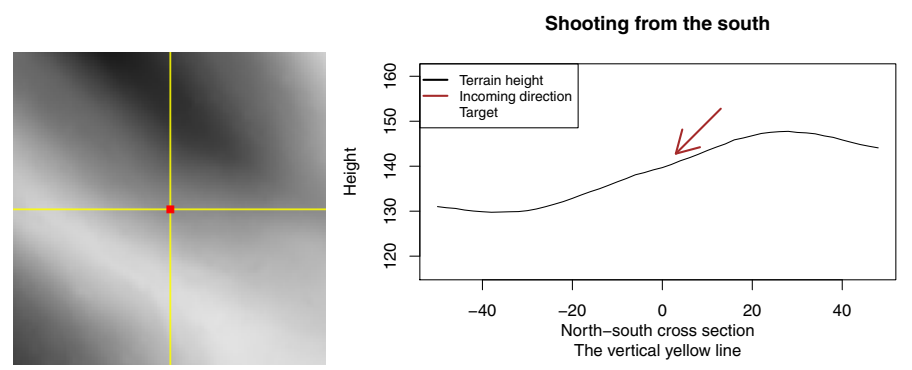

(a) Height map of the (b) Terrain profile in north-south direction. area.

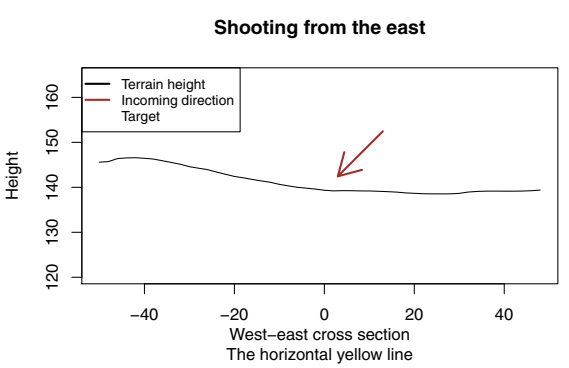

(c) Terrain profile in west-east direction.

Figure 9: Target 4 is well visible from the east and the rounds are likely to hit the hills near the target. From the south the hill gives some protection. The target position is indicated by a red dot.
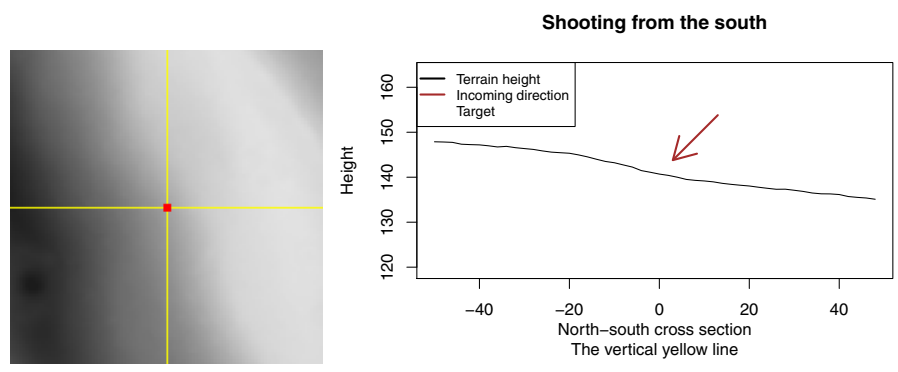

(a) Height map of the (b) Terrain profile in north-south direction. area.

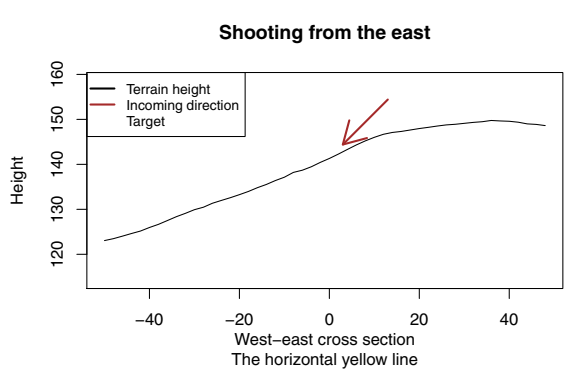

(c) Terrain profile in west-east direction.

Figure 10: Target 5 is on the south-west side of the hill so it is well protected from fire from the east, but is vulnerable from the south. The target position is indicated by a red dot. 

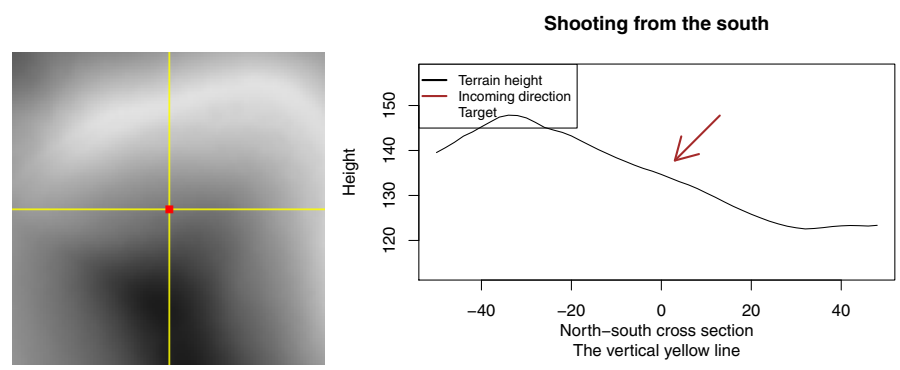

(a) Height map of the (b) Terrain profile in north-south direction. area.

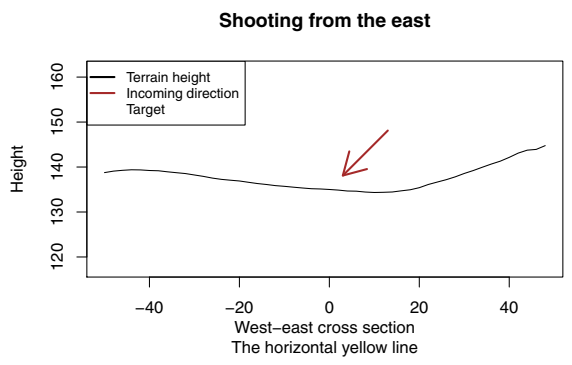

(c) Terrain profile in west-east direction.

Figure 11: Target 6. Hills cover the target from east, west and north, so rounds fired from the south are very likely to explode close to the target. The target is also high enough, so that the eastern hills do not protect it from fire from the east. The target position is indicated by a red dot.
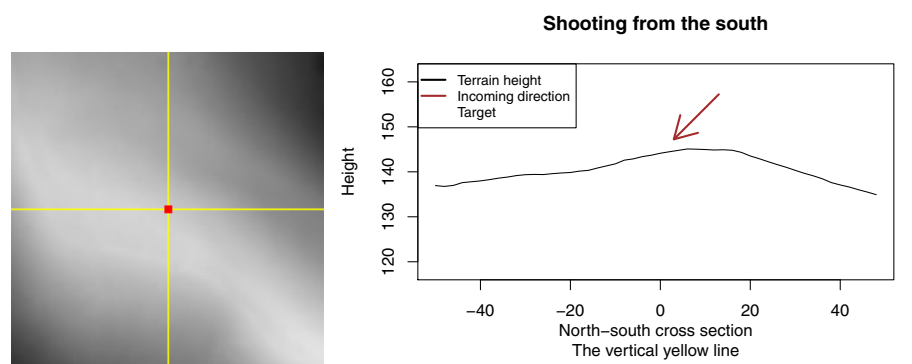

(a) Height map of the (b) Terrain profile in north-south direction. area.

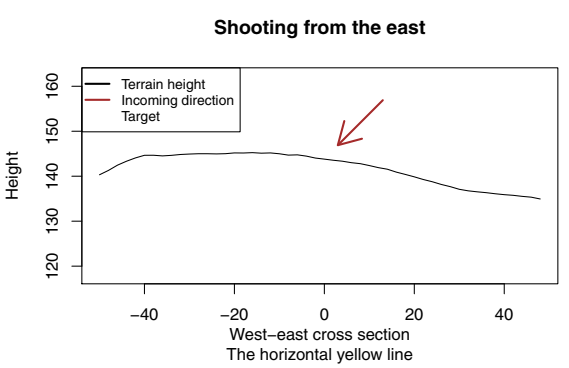

(c) Terrain profile in west-east direction.

Figure 12: Target 7 is on the north side of a small hill giving it decent protection from the south, but there is no cover to the east. The target position is indicated by a red dot.
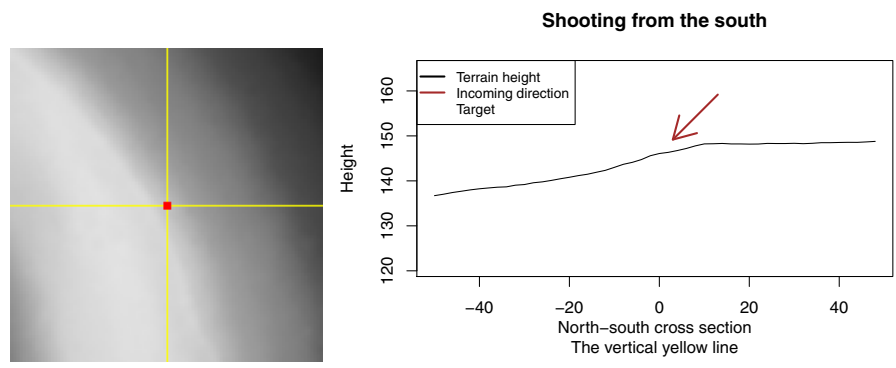

(a) Height map of the (b) Terrain profile in north-south direction. area.

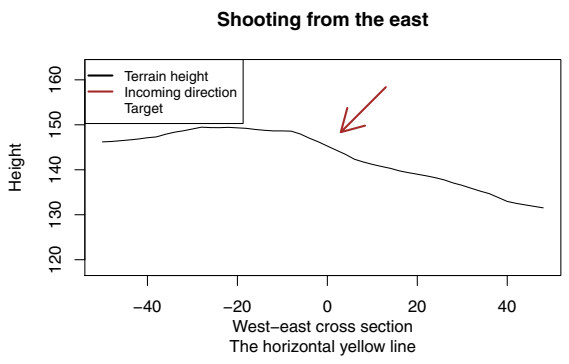

(c) Terrain profile in west-east direction.

Figure 13: Target 8 is on the east side of the hill, so it is vulnerable to fire from the east. The hill provides some protection from the south. The target position is indicated by a red dot. 


\section{Lappi, Sysikaski, Åkesson, and Yildirim}

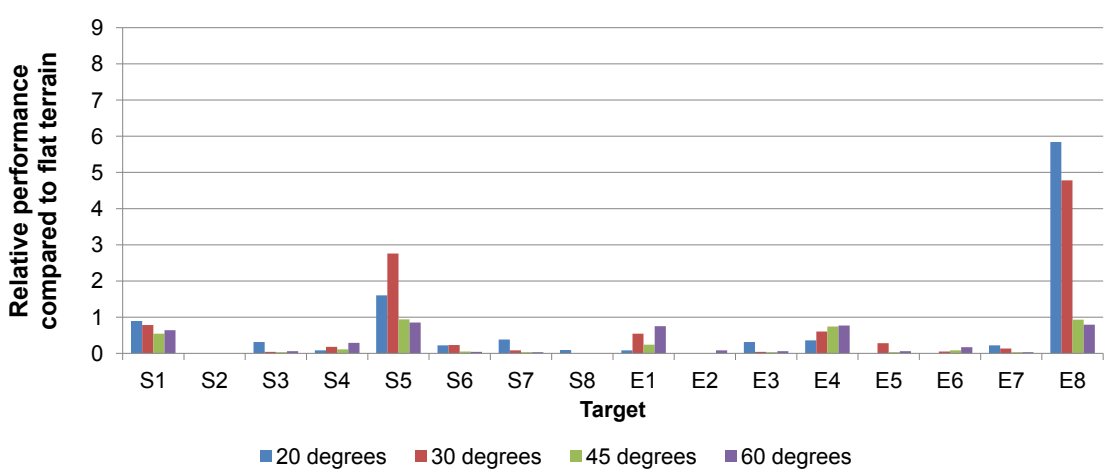

Figure 14: Relative performance of rounds compared to flat terrain for the eight targets, using a height of burst of $0.1 \mathrm{~m}$ and four different angles of fall (flat terrain =1.0). The labels $\mathrm{S} n$ and En refer to target $n$ when it is fired from south or east, respectively.

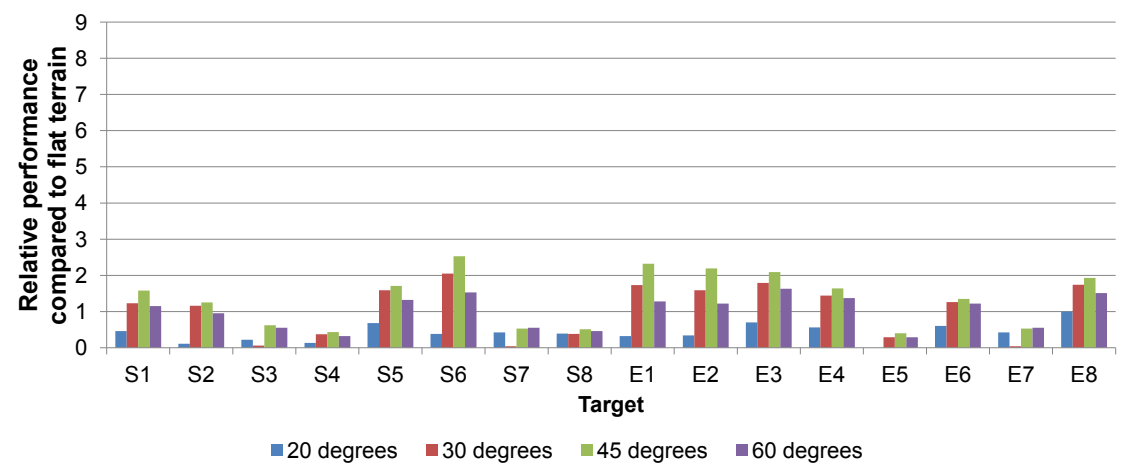

Figure 15: Relative performance of rounds compared to flat terrain for the eight targets, using a height of burst of $10 \mathrm{~m}$ and four different angles of fall (flat terrain =1.0). The labels $\mathrm{S} n$ and En refer to target $n$ when it is fired from south or east, respectively.

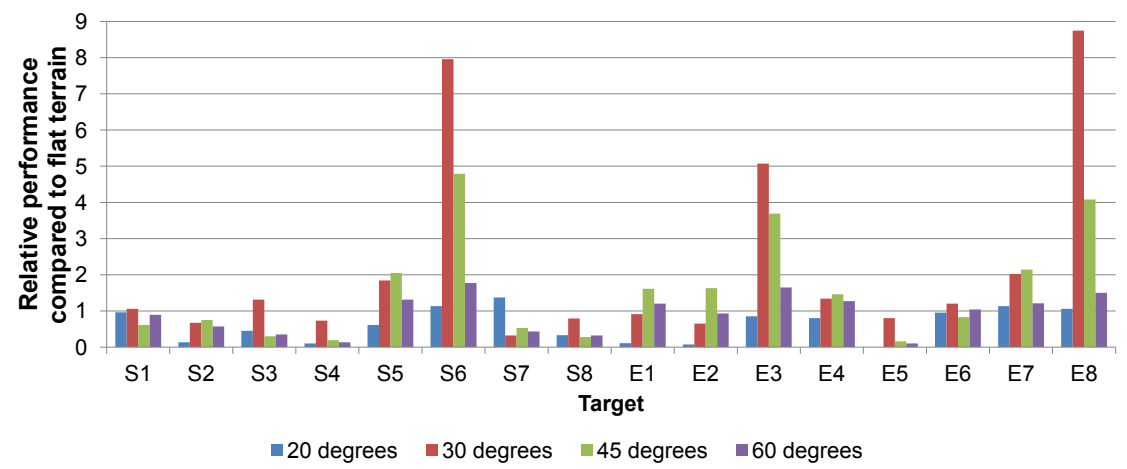

Figure 16: Relative performance of rounds compared to flat terrain for the eight targets in forest using four different angles of fall (flat terrain =1.0). The labels $\mathrm{S} n$ and En refer to target $n$ when it is fired from south or east, respectively. 


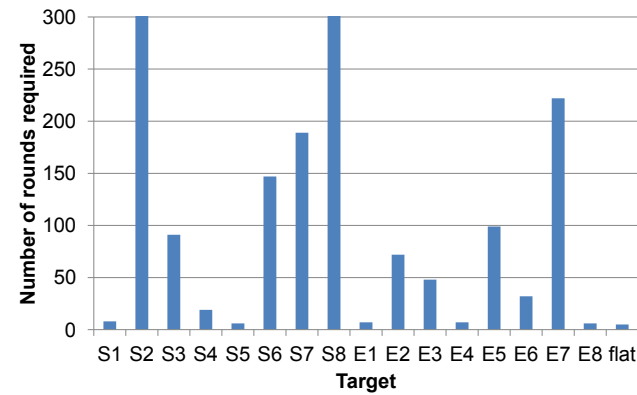

(a) Required number of rounds for a kill when using a $0.1 \mathrm{~m}$ height of burst. The bars are clamped at the value 300 .

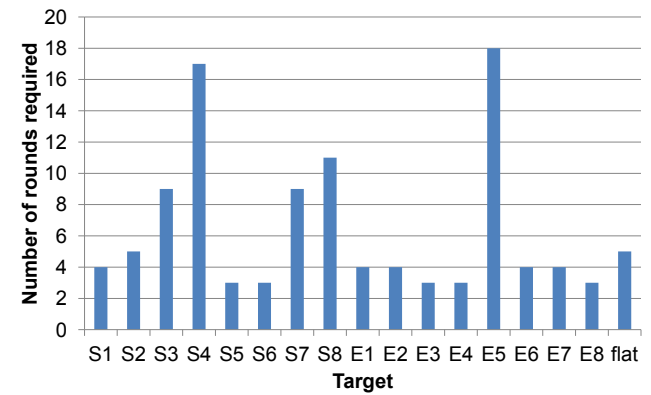

(b) Required number of rounds for a kill when using a $10 \mathrm{~m}$ height of burst.

Figure 17: Required number of rounds for $90 \%$ kill probability from $60^{\circ}$ angle of fall for different targets in rugged terrain and on flat terrain. The labels $\mathrm{S} n$ and En refer to target $n$ when it is fired from south or east, respectively. Note the different axis scale in the figures.

with the terrain explain the results. With the new simulation model for indirect fire, we can convert common sense to numbers and measures of effectiveness. The ability to study fragments and terrain effects is an improvement over traditional damage models like Carleton or cookie cutter.

Taking terrain shapes into account is very essential for getting meaningful computational results in a rough terrain. Results from the simulations imply that taking the results for flat terrain and just correcting them by some factor will not work as a general solution. Instead, one must integrate the terrain model into the calculations as presented in this paper.

Let us consider a combat situation where we have different positions for the artillery units and a detected target. The model is useful in order to determine which gun(s) is to be used (due to different directions to the target), which incoming angle should be selected, which fuze type should be used, and the amount of ammunition to be used in order to have a desired effect to the target.

For example, for target 5, with a low angle of fall, as the eastern slope protects the target and does not give the sensor the needed indication at the right place, neither impact fuze nor proximity fuze would be the best choice. In this case a time fuze would be the most effective one, as it would detonate on the top of the target.

The physical artillery simulation model has been used in tactical and technical studies and analysis, and it has been implemented in the Sandis software for that purpose (Lappi et al. 2008). The extended model, which is presented here, can be used in constructive simulations for analysis purposes, as part of training simulators for training artillery officers, and as part of indirect fire command and control systems.

\section{REFERENCES}

Åkesson, B., and E. Lappi. 2010, December. “An improved model for simulating indirect fire”. In Proceedings of the 2010 Winter Simulation Conference, edited by B. Johansson, S. Jain, J. Montoya-Torres, J. Hugan, and E. Yücesan. Piscataway, New Jersey: Institute of Electrical and Electronics Engineers, Inc.

Courtney-Green, P. R. 1991. Ammunition for the Land Battle. London, England: Brassey's Ltd.

Departments of the Army, the Navy, and the Air Force 1990. Technical Manual TM 5-1300: Structures to resist the effects of accidental explosions. Washington, DC: Departments of the Army, the Navy, and the Air Force.

Heininen, T. 2006. "A method to calculate the lethality of fragmenting ammunition". In Lanchester and Beyond-A Workshop on Operational Analysis Methodology, edited by J. S. Hämäläinen, Volume 11 of Defence Forces Technical Research Centre Publications, 19-30. Riihimäki: Defence Forces Technical Research Centre. 
Janzon, B. 1971. "Underlag för verkansberäkningar. H5. Splitters luftmotstånd. (Air resistance of fragments, in Swedish)". Technical Report FOA 2 A 2539-44, Försvarets forskningsanstalt, Stockholm.

Koskimaa, M. 1968. "Prikaatin ja ylijohdon kenttätykkikalustolle asetettavat vaatimukset ja niiden toteuttamismahdollisuudet asetekniikan viikeaikaisen kehityksen kannalta tarkasteltuna (Requirements on field artillery equipment of the brigade and high command, and their possibilities of being fullfilled regarding the recent development in arms technology)". In Tiede ja Ase - Suomen Sotatieteellisen Seuran Vuosijulkaisu N:o 26, edited by S. Simelius, K. J. Mikkola, and H. Seppälä, 160-236.

Lappi, E. 2008. "Sandis Military Operation Analysis Tool". 2nd Nordic Military Analysis Symposium, Stockholm, Sweden, November 17-18, 2008..

Lappi, E., O. Pottonen, S. Mäki, K. Jokinen, O. Saira, B. Åkesson, and M. Vulli. 2008. "Simulating indirect fire - a numerical model and validation trough field tests". 2nd Nordic Military Analysis Symposium, Stockholm, Sweden, November 17-18, 2008..

National Land Survey of Finland 2012. "Laser scanning data". Accessed 27 March 2012. http://www. maanmittauslaitos.fi/en/node/3177.

Pääesikunta (Defence Command Finland) 1984. Todennäköisyys- ja ampumaopin perusteet (Basics in probability and gunnery, in Finnish). Pääesikunta.

Rilbe, U. 1970. "Splitters genomslagsförmåga—Sammanställning av numeriska värden grundade på försök och beräkningar (Perforation capability of fragments - Compilation of numerical values based on experiments and calculations, in Swedish)". Technical Report FOA 2 A 2525-44, Försvarets forskningsanstalt, Stockholm.

Washburn, A. 2003. "Diffuse Gaussian multiple-shot probabilities”. Military Operations Research 8 (3): 59-64.

\section{AUTHOR BIOGRAPHIES}

ESA LAPPI is a Major (eng) in the Finnish Defence Forces. He received his M.Sc. in Mathematical Engineering from Helsinki University of Technology in 1991, his Phil. Lic. in Mathematics from Tampere University in 2005 and his Doctoral degree from the National Defence University in 2012. He is currently chief scientist at the Electronics and Information Technology Division of the Defence Forces Technical Research Centre in Riihimäki, Finland. His email address is esa.lappi@mil.fi.

MIKKO SYSIKASKI is a graduate student in computer science at the University of Helsinki where he has studied since 2008. He was also working as a conscript researcher at the Finnish Defence Forces Technical Research Centre in 2011-2012. His research interests include computational geometry and algorithmics. His email address is mikko.sysikaski@cs.helsinki.fi.

BERNT ÅKESSON is a Lieutenant (eng) in the Finnish Defence Forces. He received his M.Sc. in Chemical Engineering from Åbo Akademi University in Turku, Finland, in 2000 and his Doctoral degree in Process Control, also from Åbo Akademi University, in 2006. He is currently a principal scientist in operational analysis at the Electronics and Information Technology Division of the Defence Forces Technical Research Centre in Riihimäki, Finland. The focus of his work is computational combat models. His email address is bernt.akesson@mil.fi.

UǦUR ZIYA YILDIRIM is a Lieutenant Colonel in the Turkish Army. He received his B.S. and M.S. in Operations Research from the U.S. Military Academy in 1991 and from the Naval Postgraduate School in 1999 respectively. He received his Ph.D. in Industrial Engineering from Bilkent University in 2009. He is currently the chief of Joint Concept Experimentation Office in Turkish War Colleges in Istanbul, Turkey. His email address is uyildirim@ harpak.edu.tr. 